\title{
Disciplinary memory and theory development
}

\author{
Manjit S. Yadav ${ }^{1}$
}

Published online: 7 June 2017

(C) Academy of Marketing Science 2017

The cumulative nature of scientific knowledge development has attracted much attention over the years, although important questions still remain about how ideas build on one another to create a systematic progression of thought in a particular discipline. For instance, Kuhn's (1962) The Structure of Scientific Revolutions argued that this progression is perhaps not very linear. In fact, according to Kuhn, the transition from one paradigm to the next could be characterized by significant incommensurability. As scholars in a scientific community choose a specific research path for moving forward, this incommensurability often translates into complex paradigmatic decisions. These decisions, according to Kuhn, may not always be consistent with a somewhat idealistic notion of scientific progress in which all the building blocks are expected to come together neatly and sequentially. In this regard, it is important to note that other perspectives that differ from the Kuhnian argument have also emerged as the issue of scientific knowledge development has been debated and discussed (see Hunt 2010).

Regardless of how we may feel about these broader philosophical issues, most scholars can readily relate to the sense of satisfaction that accompanies the completion and eventual publication of a research project. The duration and developmental path of a project - from inception to publication does, of course, vary substantially. However, when an article enters the public domain of knowledge, we are contributing ideas that, when combined with the contributions of others, will hopefully coalesce into something meaningful. The

Manjit S. Yadav

yadav@tamu.edu

1 Mays Business School, Texas A\&M University, College Station, TX 77843, USA resulting research paths and outcomes can take a variety of forms-new ways of looking at an issue, new answers to perplexing questions, or perhaps new directions for moving forward. These possibilities may appear nebulous when an article is accepted for publication, but even a glimmer of those possibilities can be a source of much anticipation and satisfaction for authors.

To translate these possibilities into reality, it is imperative for a discipline to have mechanisms that allow potential connections between individual articles to become salient over time. However, the identification and subsequent development of such connections is by no means automatic. A set of articles on a substantive issue, no matter how interesting the constituent articles may be individually, will not self-organize into a compelling new perspective or solution to a vexing problem. It requires concerted efforts by scholars in that substantive area to carefully take stock of what has been accomplished, identify where the gaps exist, and clearly specify what is needed to address these gaps. To be effective, these efforts must respect the history of ideas as it pertains to a substantive issue, but they should also be willing to deviate - sometimes even substantially - from previous research paths. Fundamentally, what is required is a deep commitment to research endeavors that seek to carefully assemble a detailed and thoughtful portrait of what a discipline knows (and does not know) at a given point in time. This disciplinary memory, if curated assiduously over time, can then serve as a reliable foundation for moving ahead (Medema and Warren 2001). However, when such a foundation is absent or weakly developed, the long-term knowledge development mission of a discipline is likely to be hampered.

Unfortunately, the marketing discipline has failed to invest sufficient intellectual resources to curate its disciplinary memory. Such efforts are not completely absent, of course. What I'm suggesting is that we, as a discipline, need to do much 
more in this regard. Looking back rigorously should become an important priority-just as important as our quest to look ahead in our research programs. This perspective should be reflected not only in terms of research efforts, but also in terms of how we train the new generation of scholars in doctoral programs.

\section{Looking back to look ahead}

A good starting point, to spur such efforts, is to take a careful look at the overall trajectory of knowledge development in our discipline. The analysis provided by Kerin (1996) and Wilkie and Moore (2003) is very helpful in this regard, even though both articles need an update to take into account recent substantive, conceptual, and methodological developments. Kerin (1996) provides a detailed decade-by-decade discussion from 1936 to 1995. The following time periods are analyzed, each with a descriptor that reflects the dominant research perspective: 1936-1945 (Applied Economics), 1946-1955 (Managerial Activity), 1956-1965 (Quantitative Science), 1966-1975 (Behavioral Science), 1976-1985 (Decision Science), and 1986-1995 (Integrative Science). A detailed analysis of these various time periods, and how the prevailing research perspectives shaped research approaches (and specifically theory development) is beyond the scope of the arguments I wish to develop here. However, Kerin's (1996) analysis clearly shows a link between the dominant research perspective and the specific substantive, conceptual, and methodological approaches that were pursued during each decade.

For instance, during the 1936-1945 period, the prevailing "Applied Economics" perspective directed attention at commodities, institutions, and various functions performed by marketing. This perspective also shaped how scholars framed the discipline's emerging interest in advertising (specifically, as an examination of advertising's economic effects). Similarly, "Applied Economics" served as the lens to examine how nascent regulatory institutions were shaping marketing practice. Looking across the decades, it becomes evident that the dominant perspective is more than just a convenient "label"-it can have a profound impact on the substantive, conceptual, and methodological priorities of a discipline.

Wilkie and Moore (2003) provide an expansive analysis that compliments the discussion presented by Kerin (1996). Wilkie and Moore organize their discussion across "Four Eras": 1900-1920 (Founding), 1920-1950 (Formalization), 1950-1980 (Paradigm Shift), and 1980-1996 (Paradigm Shift-Intensified). Although the labels and levels of analysis are different, Wilkie and Moore's (2003) analysis results in an overarching conclusion that is fundamentally quite similar to that of Kerin (1996): carefully examining the long arc of knowledge development in a field can be very instructive. At each point along this arc, as a dominant perspective crystallizes, there are significant substantive, conceptual, and methodological implications.

Collectively, expansive analyses such as those presented by Kerin (1996) and Wilkie and Moore (2003) underscore the importance of carefully looking at our discipline using a wide-angle lens. This broader exploration doesn't have to come at the expense of on-going research efforts to focus on specific, more narrowly-construed phenomena. Such efforts must continue. What is needed is more attention to the "big picture" of knowledge development that often gets overlooked.

\section{AMS Review's editorial philosophy and initiatives}

AMS Review (AMSR) is uniquely positioned to address the issues discussed above and compliment the valuable work being done by other journals in the marketing discipline. As a journal that is focused exclusively on conceptual contributions aimed at theory development, AMSR offers both breadth and depth to examine the evolution of ideas in our field. For instance, authors can take a broad look at knowledge development in a phenomenon (e.g., the evolution of a prevailing nomological network of constructs). Or, alternatively, authors writing for AMSR can present an in-depth analysis of how the domain, conceptualization, or operationalization of a specific construct has evolved over time. The key point here is that AMSR's editorial philosophy provides a broad template of research opportunities for crafting conceptual articles that can lead to long-term advancement of the marketing discipline (for more details, see Yadav 2014). I invite marketing scholars to develop such rigorous, integrative articles. To be impactful, these articles must use the "review" portion of their article as a starting point and not as an end point; the review must provide specific insights and gaps that have clear implications for knowledge development (specifically, theory development) in a given substantive area.

To spur such expansive and integrative research efforts, $A M S R$ is currently pursuing a long-term initiative to direct attention at selected influential contributions in the marketing discipline. As part of this initiative, a number of leading scholars have developed retrospective and prospective articles based on their influential contributions to our field. We launched this initiative in the December 2015 issue with Hunt's (2015) article on Resource-Advantage theory. In the June 2016 issue, Keller (2016) wrote about customer-based brand equity. We featured Zaltman's (2016) article on imagination and theory development in the December 2016 issue. In the current issue, Jaworski and Kohli (2017) write about how they developed their original article on market orientation - one of the most highly-cited articles in our field. Jaworski and Kohli's (2017) article, like the others noted above, are accompanied by commentaries that add value 
by providing context and directions for moving forward. In forthcoming issues, $A M S R$ will continue to feature such contributions.

These articles represent just the start of a long-term scholarly conversation that $A M S R$ seeks to facilitate in the marketing discipline. In future issues, we plan to publish additional thoughtful and provocative contributions. You can join this conversation by putting AMSR on your reading list and encouraging colleagues - especially doctoral students - to do the same. I emphasize doctoral students as we need to involve the new generation of scholars more actively in conceptual research efforts aimed at theory development. In this regard, I would like to mention the AMS Review/Sheth Foundation Doctoral Competition for Conceptual Articles that we launched in 2017. This annual competition encourages doctoral students to expand their research portfolios by adding conceptual articles that will facilitate their on-going research and professional development. Directors of doctoral programs in marketing can play an invaluable role in enhancing the overall impact of this promising initiative that has significant longterm implications for our field.

Looking ahead, I would like to extend a warm welcome to the global community of scholars in marketing and related substantive areas to contribute to AMSR. Together, by developing impactful conceptual articles that inform and challenge us, we can continue the important task of strengthening the marketing discipline.

\section{References}

Hunt, S. D. (2010). Marketing theory: foundations, controversy, strategy, and resource-advantage theory. Armonk: M.E. Sharpe.

Hunt, S. D. (2015). The theoretical foundations of strategic marketing and marketing strategy: foundational premises, R-A theory, three fundamental strategies, and societal welfare. AMS Review, 5(3-4), 61-77.

Jaworski, B. J., \& Kohli, A. K. (2017). Conducting field-based, discovery-oriented research: lessons from our market orientation experience. AMS Review, 7(1-2). doi:10.1007/s13162-017-0088-5.

Keller, K. L. (2016). Reflections on customer-based brand equity: perspectives, progress, and priorities. AMS Review, 6(1-2), 1-16.

Kerin, R. (1996). In pursuit of an ideal: the editorial and literary history of the Journal of Marketing. Journal of Marketing, 60, 1-13.

Kuhn, T. (1962). The structure of scientific revolutions. Chicago: University of Chicago Press.

Medema, S., \& Warren, S. (Eds.). (2001). Historians of economics and economic thought: the construction of disciplinary memory. New York: Routledge.

Wilkie, W. L., \& Moore, E. S. (2003). Scholarly research in marketing: exploring the "4 Eras" of thought development. Journal of Public Policy \& Marketing, 22(2), 116-146.

Yadav, M. S. (2014). Enhancing theory development in marketing. AMS Review, 4(1-2), 1-4.

Zaltman, G. (2016). Marketing's forthcoming age of imagination. AMS Review, 6(3-4), 99-115. 